\title{
Role of Estradiol, Progestins, Insulines and Adipocytokines in Breast Cancer Promotion in Post-Menopausal Women
}

\author{
Christian Jamin
}

AFACS 169 Bd Haussmann, Paris, France.

Email: jamin.ch@gmail.com

Received December $28^{\text {th }}, 2009$; revised January $22^{\text {nd }}, 2010$; accepted February $3^{\text {rd }}, 2010$.

\begin{abstract}
Estrogens and artificial progestins used in hormone replacement therapy increase breast cancer risk. This seems to be due to a promoting and not initiating effect. A synergic effect of estradiol and hyperinsulinism has been shown. Insulin plays a role in the increase of breast cancer risk when associated with android obesity, sedentariness, type II diabetes, and high glycemic index food, alcohol and trans fatty acids intake. Natural menopause induces insulin resistance and does not induce a risk decrease. The role of insulin gives a new outlook on the influence of HRT in breast cancer promotion: estradiol alone, which improves insulin-sensitivity, does not increase breast cancer risk. Artificial progestins associated with estrogens increase the risk, whereas estrogens associated with progesterone do not. This could be due to the fact that artificial progestins increase insulin resistance, whereas natural progesterone does not. Adipose tissue, which is an endocrine gland, is insulin dependant. Breast cancer and its seriousness are correlated to adipocytokin circulating levels such as resistin, leptin, interleukin 1, adipocyte fatty acid-binding protein, and are inversely correlated to the level of adiponectin. Insulin could play a synergic role with sexual steroids by a direct effect and by increasing adipose tissue secretions.
\end{abstract}

Keywords: Breast Cancer, Estrogens, Progestins, Insulin, Hormone Replacement Therapy, Adipocytokin

\section{Introduction}

The fact that breast cancer mainly affects women after puberty and regresses after an ovariectomy can logically lead to the conclusion that sexual steroids play a predominant part in the genesis and the promotion of breast cancer. For numerous researchers, this predominant part has become a unique part, and consequently they have come to make estrogens a scapegoat in all epidemiological and clinical observations. A few disturbing elements like the fact that breast cancer incidence still rises after menopause, whereas it decreases sharply after hormone replacement therapy (HRT) has been stopped, raise some questions about the validity of such an approach [1,2]. A new actor, insulin, might play a predominant part in the future.

\section{Role of Sexual Steroids in the Initiation and/or Promotion of Post Menopausal Breast Cancer: State of the Art}

A Lancet meta-analysis compiled studies on the relationship between HRT and breast cancer risk and found a
1,26 RR [3]. The Women Health Initiative (WHI) study confirms this increase after 5 years of treatment [4], but only among women taking HRT before the study. It is thus impossible to evaluate the necessary HRT duration before a significant risk increase appears. The Million Women Study (MWS) [5] is in accordance with the Lancet meta-analysis and WHI. Only women with a BMI higher than $25 \mathrm{~kg} / \mathrm{m}^{2}$ have a risk increase [4].

Globally RR is low, but since spontaneous risk increases with age, this low RR could induce a high attributable risk over long treatment periods (10 or 15 years) [6]. When one considers the rapidity at which excess risk appears, plus the fact that this risk increase disappears rapidly when the treatment is stopped, plus the absence of in situ cancers increase, it is likely that there is a promotion phenomenon and not of initiation [1,2]. The arm estrogens only of WHI, as well as numerous other studies of the cohort, do not show any increase with estrogens only $(R R=0,77(0,57-1,06)[7,8]$. One study with a very long follow-up is the only one to show a very late risk increase (more than 15 years) with estrogens only [9]. 
The French E3N cohort study does not show any risk increase with the association estrogens-natural progesterone or retroprogesterone and confirms the risk increase when estrogens and synthesis progestins are associated, whatever their type [10]. All these results are concordant with the measure of apoptosis proliferation which shows a maximum promotion with the association estrogensMPA or NETA, an intermediate promotion with estrogens only and a minimum promotion with the association estrogens-progesterone and retroprogesterone or tibolone [11]. A randomized study versus placebo shows a significant breast cancer risk decrease after 3 years of tibolone [12]. Cancers discovered during HRT have a better prognosis, which could be due to a better differentiated histologic form. They are almost exclusively lobular or lobulo ductal cancers, with more hormone-sensitive forms $(\mathrm{E} 3 \mathrm{~N})$ [13-15]. Their metastatic risk evaluated over 20 years is weaker, whatever the site [16]. These favourable prognosis characteristics are observed only among women treated with estrogens associated with progestins and not among women treated with estrogens only or with the association estrogens/progesterone.

\section{The Role of Hyperinsulinism in Breast Cancer}

In the observational WHI study, each woman entering the study had an exhaustive hormonal biological testing. The correlations between the hormone levels of women when they entered the study and their subsequent breast cancer risk have shown that there is not one but two actors very predictive of this risk: blood levels of estradiol and insulin [17]. It has to be pointed out that in this study neither IGF1 nor IGFBP3 are independent risk factors. The insulin effect is not affected by the adjustment of estradiol level, and similarly the adjustment of insulin level does not affect the effect of estradiol. Therefore these two factors are independent. As of today, three others studies have evaluated in a prospective way the insulin level as a predictive breast cancer risk factor. Two of them do not find any correlation, but they included women under HRT. The last one, which did not include women under HRT, finds the same result as observational WHI. Another study showed that when a post-menopausal woman has breast cancer, her insulin level at the time of diagnosis is strongly predictive of her mortality risk after 10 years [18-21].

In another study, after stratification of insulinemia in quartiles, it has been found that the insulinemia superior quartile versus the inferior quartile gives a mortality RR at 8 and of recurrence at 4 [22]. In the MA 14 study, insulin resistance is associated with survival reduction without recurrence [23]. Finally a preliminary work shows that when insulin receptors are measured in tumours, tumours with the most receptors have a worse prognosis.

Insulin stimulates normal and cancer cell proliferation and has a promoting effect on breast tumours in the animal. The insulin receptor is over expressed in breast cancer, and in woman hyperinsulinism is associated with an increase in estrogen ovarian production, a decrease of estradiol carrier protein (SHBG), and therefore an increase of free estradiol $[15,24-29]$. The fixation of insulin to its receptor on breast cancer cell increases phosphatidylinositolkynase and kinase MAP activity. Furthermore, insulin activates estrogens receptor alpha-mediated transcription in breast cancer cell lines, even in the absence of estradiol. In addition estradiol activates the MAPK pathway of insulin. Finally, in breast cancer cell culture medium, estradiol has a proliferative effect only in the presence of growth factors such as insulin.

This throws a different light over numerous situations that could not be explained until now. With menopause comes insulin resistance: this could explain the fact that breast cancers do not diminish at menopause, but do diminish rapidly when HRT is stopped $[1,3,30]$. Overweight is a recognised breast cancer risk factor after menopause, whereas it is rather protective before menopause. In this regard we know that pre-menopausal gynoïd obesity does not alter insulin-sensitivity, whereas post-menopausal android obesity is associated with insulin-resistance [31].

Metabolic syndrome and its clinical marker, waistto-hip ratio, multiplies by 2 breast cancer risk, and this independently from testosterone level. Furthermore this ratio is predictive of breast cancer mortality at the time cancer is discovered [32-35].

The level of HDL cholesterol, a marker of insulin sensitivity, is inversely correlated to insulinemia and breast cancer risk $[35,36]$.

Nowadays physical activity is admitted to be a protective factor from breast cancer, as well as a reduction factor of breast cancer mortality $[18,37,38]$. This protection also exists among women with a BRCA1/2 mutation [39]. In increasing muscular mass, physical activity improves insulin-sensitivity and thus reduces circulating insulin level, including after breast cancer [40].

High trans fatty intakes are associated with a high breast cancer risk $\mathrm{RR}=1,75(1,08-2,83)$ in $\mathrm{E} 3 \mathrm{~N}$, and with a higher insulin resistance risk and diabetes [41,42]. Alcohol, which is a recognized breast cancer risk factor after menopause, reduces insulin-sensitivity and increases insulin receptors in tumours [43]. Food glycemic index is a marker of insulinic response to their ingestion. The more food with high glycemic index a woman eats, the higher her breast cancer risk $[44,45]$.

Type II diabetics, non insulin-dependent, have a hyperinsulinism and a 1,2 breast cancer relative risk. Studies have shown that when these type II diabetes are treated with metformin, there is a reduction of breast 
cancer mortality, whereas a treatment by sulfonyl ureas or by insulin increases this mortality [46-48].

\section{Interactions between Insulin Sensitivity and HRT}

This estradiol/insulin synergy enlightens the relationship between HRT and breast cancer risk. We know that estrogens given at mean doses by oral or transcutaneous routes improve insulin-sensitivity and thus diminish insulinemia, whereas oral estrogens given at high doses and/or associated with artificial progestin, in particular MPA, increase insulin-resistance [30]. Furthermore the PEPI study has shown that contrary to MPA, natural progesterone does not alter insulin-sensitivity, which is improved by equine conjugated estrogens [49]. Thus it could be because of insulin that HRT containing artificial progestins increase breast cancer risk, that estrogens only do not increase or maybe even reduce this risk, and that, contrary to progestins, progesterone associated with estrogens have no deleterious effect $[7,10]$.

Moreover, deleterious effects of HRT containing artificial progestin are maximum in immediate postmenopause when insulin resistance has not set in. At distance from menopause, the same treatments have a weaker effect because insulin resistance linked to menopause has already had its own effect [50].

\section{Indirect Effects of Insulin on Breast Cancer Risk: Role of Adipose Tissue and Adipocytokines}

Adipose tissue secretes hormones called adipocytokines. The volume of adipose tissue is increased by insulin. Thus insulin could play a direct part on cancerous cells, but could also have an indirect effect in modifying adipocytokines secretions. Among these adipocytokines, resistin is higher in women with breast cancer, is associated with cancer seriousness and is partly responsible for insulin-resistance. Leptin, another adipocytokine, is also high among women with breast cancer, metastatic in particular, and increases aromatase activity in intramammary production of estrogens. Interleukin 1, also secreted by adipose tissue, has a level correlated to breast cancer risk and progression. Adipocyte fatty acid binding protein is predominantly expressed in the cytosol of mature adipocytes and has been described as associated with obesity markers and obesity-related diseases. Adipocyte fatty acid binding protein is recognized to affect insulin sensitivity, lipid metabolism, and an inflammatory response associated with atherosclerosis. Adipocyte fatty acid binding protein has been recently shown to be significantly associated with breast cancer risk. Finally adiponectin is lowered in case of metabolic syndrome, type II diabetes and android obesity. It is low in women with breast cancer and its level is inversely associated with node invasion. It increases mammary cancer cell apoptosis and diminishes neo-vascularization [51-54].

\section{Conclusions}

Thus the insulin/estrogens couple has a synergic and independent effect on breast cancer risk. Estradiol does not promote these cancers in the absence of hyperinsulinism. Insulin-dependent adipose tissue could also be one of the actors of this synergy, through adipocytokines.

This approach gives new elements for a better understanding of the relationship between hormones and breast cancer, and might in the future originates in new therapeutic and/or preventive strategies in breast cancer.

\section{REFERENCES}

[1] R. T. Chlebowski., L. H. Kuller, R. L. Prentice, M. L. Stefanick, and E. Manson, "Breast cancer after use of estrogen plus progestin in post menopausal women," New England Journal of Medicine, Vol. 360, pp. 573-587, 2009.

[2] P. M. Ravdin, K. A. Cronin, N. Howlader, C. D. Berg, and R. T. Chlebowski, "The decrease in breast-cancer incidence in 2003 in the United States," New England Journal of Medicine, Vol. 356, pp. 1670-1674, 2007.

[3] Collaborative Group on Hormonal Factor in Breast Cancer, "Breast cancer and hormone replacement therapy: Collaborative reanalysis of data from 51 epidemiological studies of 52705 women with breast cancer and 108411 women without breast cancer," Lancet, Vol. 350, pp. 1042-1059, 1997.

[4] J. E. Rossouw, G. L. Anderson, R. L. Prentice, A. Z. LaCroix, and C. Kooperberg, Writing group for the WHI "Risks and benefits of estrogen plus progestin in healthy postmenopausal women: principal results," From the Women's Health Initiative randomized controlled trial, Journal of the American Medical Association, Vol. 288, pp. 321-333, 2002.

[5] V. Beral, Million Women Study Collaborators, "Breast cancer and hormone-replacement therapy in the Million Women Study," Lancet, Vol. 362, pp. 419-427, 2003.

[6] M. Ewertz, L. Mellemkjaer, H. Poulsen, S. Friis, and H. T. Sørensen, "Hormone use for menopausal symptoms and risk of breast cancer. A Danish cohort study," British Journal of Cancer, Vol. 92, pp. 1293-1297, 2005.

[7] G. L. Anderson, M. Limacher, A. R. Assaf, T. Bassford, and S. A. Beresford, "Effects of conjugated equine estrogen in postmenopausal women with hysterectomy. The Women's Health Initiative randomized controlled trial," Journal of the American Medical Association, Vol. 291, pp.1701-1712, 2004.

[8] W. Y. Chen, J. E. Manson, S. E. Hankinson, B. Rosner, and M. D. Holmes, "Unopposed estrogen therapy and the risk of invasive breast cancer," Archives of Internal Medicine, Vol. 166, pp. 1027-1032, 2006.

[9] C. I. Li, K. E. Malone, P. L. Porter, N. S. Weiss, and M. T. Tang, "Relationship between long durations and different 
regimens of hormone therapy and risk of breast cancer," Journal of the American Medical Association, Vol. 289, pp. 3254-3263, 2003.

[10] A. Fournier, F. Berrino, E. Riboli, V. Avenel, and F. Clavel-Chapelon, "Breast cancer risk in relation to types of hormone replacement therapy in the E3N-EPIC cohort," International Journal of Cancer, Vol. 114, pp. 448-454, 2005.

[11] C. E. Wood, T. C. Register, C. J. Lees, H. Chen, and S. Kimrey, "Effects of estradiol with micronized progesterone or medroxyprogesterone acetate on risk markers for breast cancer in postmenopausal monkeys," International Journal of Cancer, Vol. 101, pp. 125-134, 2007.

[12] S. Cummings, B. Ettinger, P. Delmas, P. Kenemans, and V. Stathopoulos, "The effects of Tibolone in older postmenopausal women," New England Journal of Medicine, Vol. 359, pp. 697-708, 2008.

[13] W. Chen, D. Pettiti, and A. Geiger, "Mortality following development of breast cancer while using oestrogen or oestrogen plus progestin: A computer record-linkage study," British Journal of Cancer, Vol. 93, pp. 392-398, 2005.

[14] A. Fournier, F. Berrino, and F. Clavel-Chapelon, "Unequal risks for breast cancer associated with different hormone replacement therapies: Results from the E3N cohort study," British Journal of Cancer, Vol. 107, pp. 103-111, 2008.

[15] C. Schairer, M. Gail, C. Byrne, P. S. Rosenberg, and S. R. Sturgeon, "Estrogen replacement therapy and breast cancer survival in a large screening study," Journal of the National Cancer Institute, Vol. 91, pp. 264-270, 1999.

[16] F. Schuetz, I. J. Diel, M. Pueschel, T. von Holst, and E. F. Solomayer, "Reduced incidence of distant metastases and lower mortality in 1072 patients with breast cancer with a history of hormone replacement therapy," American Journal of Obstetrics and Gynecology, Vol. 196, pp. 342. e1-9, 2007.

[17] M. J. Gunter, D. R. Hoover, H. Yu, S. WassertheilSmoller, and T. E. Rohan, "Insulin, insulin-like growth factor-1, and risk of breast cancer in postmenopausal women," Journal of the National Cancer Institute, Vol. 101, pp. 48-60, 2009.

[18] M. J. Borugian, S. B. Sheps, C. Kim-Sing, C. Van Patten, and J. D. Potter, "Insulin, macronutrient intake, and physical activity: are potential indicators of insulin resistance associated with mortality from breast cancer?" Cancer Epidemiol Biomarkers Prevention, Vol. 13, pp. 1163-1172, 2004.

[19] M. L. Garmendia, A. Pereira, M. E. Alvarado, and E. Atalah, "Relation between insulin resistance and breast cancer among chilean women," Annals of Epidemiology, Vol. 17, pp. 403-409, 2007.

[20] R. Kaaks, E. Lundin, S. Rinaldi, J. Manjer, and C. Biessy, "Prospective study of IGF-I, IGF-binding proteins, and breast cancer risk, in northern and southern Sweden," Cancer Causes Control, Vol. 13, pp. 307-316, 2002.

[21] P. J. Mink, E. Shahar, W. D. Rosamond, A. J. Alberg, and
A. R. Folsom, "Serum insulin and glucose levels and breast cancer incidence," American Journal of Epidemiology, Vol. 156, pp. 349-352, 2002.

[22] P. Goodwin, M. E. Ennis, K. Pritchard, M. Trudeau, and J. Koo, "Fasting insulin and out come in early-stage breast cancer: Results of a prospective cohort study," Journal of Clinical Oncology, Vol. 20, pp. 42-51, 2001.

[23] M. N. Pollak, J. W. Chapman, L. Shepered, D. Meng, and P. Richardson, "Insuline resistance, estimed by serum C-peptide level, is associated with reduced event-free survival for post menopausal women in NCIC CGT MA.14 adjuvant-breast cancer trial," Journal of Clinical Oncology, Vol. 24, pp. 524, 2006.

[24] D. Ish-Shalom, C. T. Christoffersen, P. Vorwerk, P., N. Sacerdoti-Sierra, and R. M. Shymko, "Mitogenic properties of insulin and insulin analogues mediated by the insulin receptor," Diabetologia, Vol. 40, Supplement No. 2, pp. S25-31, 1997.

[25] L. Poretsky and M. F. Kalin, "The gonadotropic function of insulin," Endocrine Reviews, Vol. 8, No. 132-141, 1987.

[26] S. M. Shafie and F. H. Grantham,"Role of hormones in the growth and regression of human breast cancer cells (MCF-7) transplanted into athymic nude mice," Journal of the National Cancer Institute, Vol. 67, pp. 51-56, 1981.

[27] M. Pugeat, J. C. Crave, M. Elmidani, M. H. Nicolas, and M. Garoscio-Cholet, "Pathophysiology of sex hormone binding globulin (SHBG): Relation to insulin," Journal of Steroid Biochemistry and Molecular Biology, Vol. 40, pp. 841-849, 1991.

[28] A. Belfiore, "The role of insulin receptor isoforms and hybrid insulin/IGF-1 receptors in human cancer," Current Pharmaceutical Design, Vol. 13, pp. 671-686, 2007.

[29] J. Chappell, W. Leitner, S. Solomon, I. Golovchenko, and M. Goalstone, "Effect of insulin on cell cycle progression in MCF-7 breast cancer cells," Journal of Biological Chemistry, Vol. 276, pp. 38023-38028, 2001.

[30] S. R. Lindheim, S. C. Presser, E. C. Ditkoff, M. A. Vijod, and F. Z. Stanczyk, "A possible bimodal effect of estrogen on insulin sensitivity in postmenopausal women and the attenuating effect of added progestin," Fertil Steril, Vol. 60, pp. 664-667, 1993.

[31] G. K. Reeves, K. Pirie, V. Beral, J. Green, and E. Spencer, "Cancer incidence and mortality in relation to body mass index in the Million Women Study: Cohort study." British Medical Journal, Vol. 335, pp. 1134, 2007.

[32] B. S. Connolly, C. Barnett, K. N. Vogt, J. Stone, and N. F. Boyd, "A meta analysis of published literature on waistto-hip ratio and risk of breast cancer," Nnutrition and Cancer, Vol. 44, pp. 127-138, 2002.

[33] N. Kumar, A. Cantor, K. Allen, and C. Cox, "Android obesity at diagnosis and breast cancer carcinoma survival," Cancer, Vol. 88, pp. 2751-2757, 2000.

[34] P. Pasanisi, F. Berrino, M. de Petris, E. Venturelli, and A. Mastroianni, "Metabolic syndrome as a pronostic factor for breast cancer recurrences," International Journal of Cancer, Vol. 119, pp. 236-238, 2006. 
[35] B. A. Stoll, "Upper abdominal obesity, insulin resistance and breast cancer risk," International Journal of Obesity and Related Metabolic Disorders, Vol. 26, pp. 747-753, 2002.

[36] A. S. Furberg, M. B. Veierod, T. Wilsgaard, L. Berstein, and I. Thune, "Serum high-density liporotein cholesterol, metabolic profile, and breast cancer risk," Journal of the National Cancer Institute, Vol. 96, No. 15, pp. 1152-1160, 2004.

[37] M. D. Holmes, W. Y. Chen, D. Feskanich, C. H. Kroenke, and G. A. Colditz, "Physical activity and survival after breast cancer diagnosis," Journal of the American Medical Association, Vol. 293, pp. 2479-2486, 2005.

[38] J. A. Ligibel, N. Campbell, A. Partridge, W. Y. Chen, and T. Salinardi, "Impact of a mixed strength and endurance exercise intervention on insulin levels in breast cancer survivors," Journal of Clinical Oncology, Vol. 26, pp. 907-912, 2008.

[39] A. Pijpe, P. Manders, R. M. Brohet, J. M. Collée, and S. Verhoef, "Physical activity and the risk of breast cancer in BRCA 1-2 mutation carriers." Breast Cancer Research, 2009.

[40] A. S. Fairey, K. S. Courneya, C. J. Field, G. J. Bell, L. W. Jones, and J. R. Mackey, "Effect of exercise training on fasting insulin, insulin resistance, insulin-like growth factors, and insulin like growth factor binding proteins in post menopausal breast cancer survivors: A randomised controlled trial," Cancer Epidemiol Biomarkers and Prevention, Vol. 12, pp. 721-727, 2005.

[41] V. Chajès, A. C. Thiébaut, M. Rotival, E. Gauthier, and V. Maillard, "Association between serum trans-monounsaturated fatty acids and breast cancer risk in the E3NEPIC Study," American Journal of Epidemiology, Vol. 167, pp. 1312-1320, 2008.

[42] U. Risérius, "Trans fatty acids and insulin resistance," Atheroscler, Supplement Vol. 7, pp. 37-39, 2006.

[43] B. A. Stoll, "Alcohol intake and late-stage promotion of breast cancer," European Journal of Cancer, Vol. 35, pp. 1653-1658, 1999.

[44] L. S. Augustin, L. Dal Maso, C. La Vecchia, M. Parpinel, and E. Negri, "Dietary glycemic index and glycemic load, and breast cancer risk: A case-control study," Annals of Oncology, Vol. 12, pp. 1533-1538, 2001.
[45] C. R. Jonas, M. L. Mc Cullough, L. R. Teras, K. A. Walker-Thurmond, and M. J. Thun, "Dietary glycemic index, glycemic load, and risk of incident breast cancer in postmenopausal women," Cancer Epidemiol Biomarkers Prevention, Vol. 12, pp. 573-577, 2003.

[46] S. Bowker, P. Veugelers, S. Majumdar, and J. Johnson, "Increased cancer-related mortality for patients with type 2 diabetes who use sulfonylureas or insulin," Diabetes Care, Vol. 29, pp. 254-258, 2006.

[47] S. Larsson, C. Mantzoros, and A. Wollk, "Diabetes mellitus and risk of breast cancer: A meta analysis," International Journal of Cancer, Vol. 121, pp. 856-862, 2007.

[48] P. Muty, T. Quattrin, B. J. B. Grant, V. Krogh, and A. Micheli, "Fasting glucose is a risk factor for breast cancer: a prospective study," Cancer Epidemiol Biomarkers Prevention, Vol. 11, pp. 1361-1368, 2002.

[49] E. Barrett-Connor, S. Slone, G. Greendale, D. KritzSilverstein, and M. Espeland, "The Postmenopausal Estrogen/Progestin Interventions Study: Primary outcomes in adherent women," Maturitas, Vol. 27, pp. 261-274, 1997.

[50] A. Fournier, S. Mesrine, M. C. Boutron-Ruault, and F. Clavel-Chapelon, "Estrogen-progestogen menopausal hormone therapy and breast cancer: Does delay from menopause onset to treatment initiation influence risks?" Journal of Clinical Oncology, 2009.

[51] W. K. Hou, Y. X. Xu, T. Yu, L. Zhang, and W. W. Zhang, "Adipocytokines and breast cancer risk," Chinese Medical Journal, Vol. 120, pp. 1592-1596, 2007.

[52] J. H. Kang, B. Y. Yu, and D. S. Youn, "Relationship of serum adiponectin and resistin levels with breast cancer risk," Journal of Korean Medical Science, Vol. 22, pp. 117-121, 2007.

[53] S. Perrier, F. Caldefie-Chézet, and M. P. Vasson, "IL-1 family in breast cancer: Potential interplay with leptin and other adipocykine," FEBS letter, Vol. 583, pp. 259-265, 2009.

[54] K. Hancke, D. Grubeck, N. Hauser, R. Kreienberg, and J. M. Weiss, "Adipocyte fatty acid-binding protein as a novel prognostic factor in obese breast cancer patients," Breast Cancer Research and Treatment, Vol. 119, pp. 367-377, 2010. 